\title{
The Attribution Cube and Reactions to Educational Outcomes
}

\author{
Donelson R. Forsyth and James H. McMillan \\ Virginia Commonwealth University
}

\begin{abstract}
Hypotheses derived from Kelley's cube model of causal inferences were lested in an educational setting by relating high and low students' attributions to reported affect and expectations. In general, low and high scoring students clustered in different cells of the cube, with high scoring students claiming their scores were nondistinctive, but low scorers emphasizing (a) distinctiveness, (b) high consensus and consistency, or (c) low consensus and consistency. Predictions concerning estimates of distinctiveness, consistency, and consensus and their relation to affect and expectations were also supported, since the cube model appeared to adequately summarize sources of causal information found in the classroom.
\end{abstract}

Analyses of students' cognitive reaction to their educational outcomes have begun stressing the role of attributional processes (e.g., Covington \& Berry, 1976; Weiner, 1979). According to this perspective, when students discover they have done well or done poorly in a classroom exercise, they search for the causes of this outcome anddepending on their attributional conclusions-experience various affective reactions, shifts in expectations, and changes in motivation. Although applications of attribution in educational settings have relied primarily on Heider's (1958) basic model of attributions, other theories--such as Kelley's cube and schemata models $(1967,1971)$ and Jones' theory of correspondent inferences (Jones, 1978; Jones \& Davis, 1965)-also provide frameworks for the interpretation of causal inference. To examine the theoretical utility of one of these approaches, Kelley's cube model, the current investigation tested the theory's predictions in the context of the college classroom.

According to Kelley $(1967,1971)$, in most situations people formulate causal inferences by attending to three sources of attribution information: distinctiveness, consistency, and consensus. Distinctiveness, at least in an educational context, is the extent to which a behavior is unique to a particular setting

Requests for reprints should be sent to Donelson R. Forsyth, Department of Psychology, Virginia Commonwealth University, 810 West Franklin Street, Richmond, Virginia 23284. or is much like what occurs in many other settings. For example, if a student dislikes math, the student will assess distinctiveness by considering whether only math is viewed with disfavor, or if many school subjects are rejected as well. Consistency is an assessment of behavior in similar situations in the past. Has this student always disliked math or does the feeling only apply to the present teacher, school, unit, or classroom? Consensus information is gathered by comparing personal reactions with other people's reactions. Do all the students in the class hate math, or is the student alone in this opinion?

Kelley presents these three dimensions as the axes of a cube that describes the types of information attributors utilize (see Figure 1). For the simplified case in which values on each dimension are either high or low, the model describes eight configurations of distinctiveness, consistency, and consensus. According to Kelley (1967, p. 196), attributors emphasize external causes "when evidence exists as to the distinctiveness, consistency, and consensus of the appropriate effects" (Cell 1 of Figure 1). In the example, the student's reaction to math class is perceived to be produced by something in the educational setting if the student likes his or her other subjects (high distinctiveness), the student does not waver in his or her rejection of the class (high consistency), and other students express a similarly negative attitude (high consensus). In contrast, "person attribution will be more frequent 


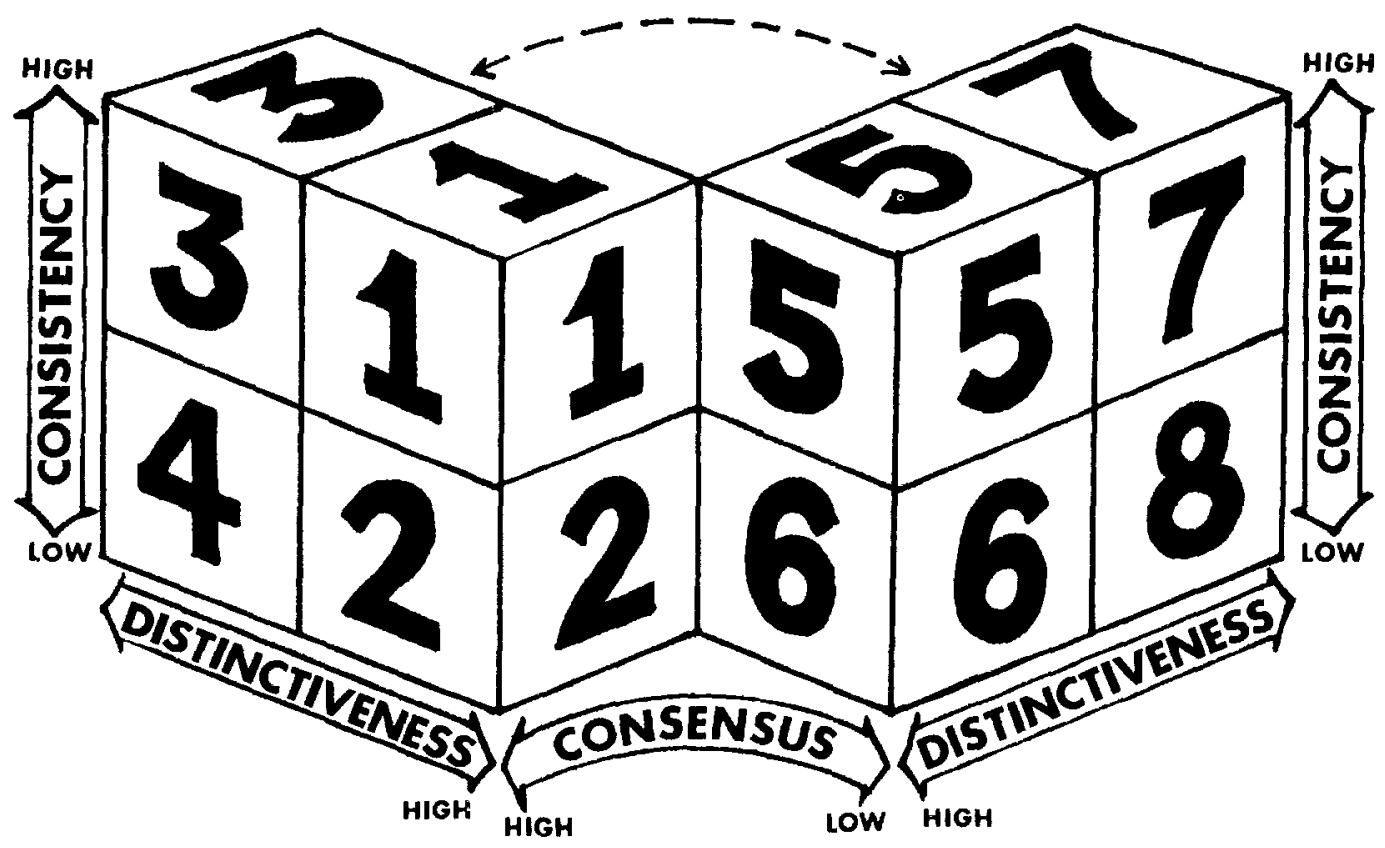

Figure 1. The eight cells of Kelley's attribution cube applied to an educational setting.

when a response is characterized by low consensus, low distinctiveness, and high consistency" (McArthur, 1972, p. 172). In other words, if few other students dislike the class, the student in question seems to negatively evaluate many different subjects, and the student continually rejects math (Cell 7), then something about the student is a more likely cause. Thus Kelley's model provides a parsimonious framework for understanding the cognitive processes through which causal attributions are formed. Moreover, the three factors described by Kelley, by emphasizing the importance of past reactions and social comparison processes, seem to adequately summarize causal information available in an educational setting.

This study tested (a) the extent to which Kelley's cube describes students' attributions and (b) the relationship of distinctiveness, consistency, consensus, and outcome to expectations and affect. College students were given feedback concerning their score on a major examination and were then asked to record their estimates of distinctiveness (Is the grade similar to grades received on tests in other subjects?), consistency (Is the current grade similar to grades earned on previous tests in this class?), and consensus (Did the majority of the other students get a similar grade, a better grade, or a worse grade?). Based on these responses, students were assigned to one of the eight cells of the Kelley attribution cube: 2 (high vs. low distinctiveness) $\times 2$ (high vs. low consistency) $\times 2$ (high vs. low consensus).

Three sets of hypotheses were developed with regard to (a) the distribution of high and low scoring students in the eight cells of the cube, (b) expectations concerning future performance, and (c) affective reactions to the test feedback. Because past research has repeatedly shown that people generally prefer to take more responsibility for their successes than their failures (Covington \& Omelich, 1979; Forsyth \& Schlenker, 1977; Weary, 1979), we anticipated that high and low scorers would differ when describing the distinctiveness, consensus, and consistency of their test scores. Specifically, we hypothesized the following:

1. High scorers will tend to describe their scores as low in distinctiveness, low in consensus, and high in consistency with past scores (e.g., I do well in all my classes/Although many people did poorly on the test, 
I managed to do quite well/I always do well in this class).

2. Low scorers will tend to describe their scores as high in distinctiveness and consensus (e.g., But I'm doing great in my other classes/Everybody did poorly on that test). Because students could externalize low scores by emphasizing either high consistency ("These tests are so unfair I always do poorly") or low consistency ("I've gotten good grades in here before; this test must have been too tricky"), no differences in low scorers' emphasis of high versus low consistency were predicted.

A second set of hypotheses focused on expectations and the three attributional dimensions. Although all three dimensions are posited to be related to expectations, research suggests that two dimensions-consistency and distinctiveness - are more important than the consensus dimension (e.g., McArthur, 1972; Orvis, Cunningham, \& Kelley, 1975). In theory, individuals faced with the task of formulating predictions of future events tend to assume that past outcomes, if consistent, are good reflections of future outcomes (Ostrove, 1978). If, however, past outcomes have been inconsistent (sometimes positive, sometimes negative), then prediction of the future becomes more complex as the attributor is forced to rely more heavily on distinctiveness cues and consensus cues. Applied to the educational setting, the theory suggests that:

3. When consistency over time is high, high scoring students will report very positive expectations and low scoring students will report very negative expectations.

4. When past outcomes have been inconsistent, expectations will be more closely associated with distinctiveness and consensus. Specifically, among students who feel their scores are inconsistent over time, (a) high scoring students will report the most positive expectations and (b) low scoring students will report the most negative expectations when they believe their score is low in distinctiveness and consensus.

The third set of hypotheses is related to affective reactions. Although the relationship between the three attributional dimensions of the cube model and affective reactions has never been empirically examined, other studies of attribution-affect linkages (e.g., Covington \& Omelich, 1979; Weiner, Russell, \& Lerman, 1978, 1979) suggest that students in different parts of the cube should vary in their affective reactions. Although high scorers typically report more positive reactions than low scorers (e.g., Covington \& Omelich, 1979; Forsyth \& McMillan, 1981), when the outcome is internalized, low scorers should feel inadequate and sad while high scorers feel happy and competent. If, however, the outcome is externalized, a good score creates less selfsatisfaction and a poor score evokes less self-condemnation. Based on this simple internal/external attribution-affect linkage hypothesis, we predicted:

5. High scorers will report (a) the most positive affective reactions when they feel their outcome is low in distinctivenes, low in consensus, and high in consistency and (b) the most negative affective reactions when distinctiveness, consensus, and consistency are all high.

6. Low scorers will report (a) the most negative affective reactions when they feel their outcome is low in distinctiveness, low in consensus, and high in consistency and (b) the most positive affective reactions when distinctiveness, consensus, and consistency are all high.

\section{Method}

\section{Subjects}

The 232 college students who participated in the study were enrolled in one of three large introductory psychology classes. Fifty-three were black, 144 were female, and 158 were first year students. They ranged in age from 17 to 32 years $(M=19.3)$.

\section{Procedure}

All data were collected on the class day immediately following administration of the third course examination. During the first few minutes of class, the course instructor presented the distribution of grades curve to the class, and then returned the graded multiple choice examinations. Subjects who received As or Bs were designated high scoring students $(n=120)$, whereas those receiving $\mathrm{C}$ grades or lower were labeled low scoring students $(n=112)$.

After students received and understood their examination grades, they were asked to complete, anonymously, a "Standard Test Rating Form" that would supposedly provide their instructor with information regarding their reactions to and appraisals of the test. 
Table 1

Descriptive Statistics for Attribution Variables

\begin{tabular}{|c|c|c|c|c|c|c|}
\hline \multirow[b]{2}{*}{ Variable } & \multirow[b]{2}{*}{$M$} & \multirow[b]{2}{*}{$M d n$} & \multirow[b]{2}{*}{$S D$} & \multicolumn{3}{|c|}{$n$} \\
\hline & & & & Overall & High group & Low group \\
\hline Distinctiveness & 4.54 & 5 & 2.49 & 232 & 112 & 120 \\
\hline Consistency & 6.29 & 6 & 2.37 & 232 & 130 & 102 \\
\hline Consensus & 5.77 & 5 & 1.89 & 232 & 126 & 106 \\
\hline
\end{tabular}

Note. Higher scores indicate greater distinctiveness, consistency, and consensus.

Three of the items on this questionnaire measured the student's location in the attribution cube. Distinctiveness was assessed by asking "Is this grade typical of how you are doing in your other classes?"; consistency by asking "Is this grade about the same as your past grades on tests in this class?"; and consensus by asking "Do you think a very large proportion of the class got about the same grade on this test that you did?" All questions were followed by 9-point scales with labeled endpoints. Respondents could then be assigned to one of the eight cells of the attribution cube by dividing subjects at the median on each item. Thus, all the students were identified as low versus high in distinctiveness, low versus high in consistency, and low versus high in consensus. Descriptive statistics for the attributional dimensions are presented in Table 1.

Expectations concerning future outcomes and affective reactions to the test were also assessed via this questionnaire. The expectations item asked "How well do you expect to do on future tests in this class?" and was followed by a 9-point scale ranging from "very poorly" to "very well." Affect was assessed by asking subjects to rate their feelings on a series of 169 -point adjective scales with gradations identified by four verbal labels. These items, which have been used in previous research (Forsyth \& McMillan, 1981), included: unrelaxed-relaxed; competent-incompetent; happyunhappy; disgusted-delighted; frustrated-fulfilled; unpleasantly surprised-pleasantly surprised; tensecalm; dissatisfied-satisfied; shame-pride; displeased- pleased; inadequate-adequate; bad-good; discontentcontent; upset-composed; unpleasantly astonishedpleasantly astonished; and depressed-elated.

\section{Results and Discussion}

\section{Attribution Cube Patterns}

Table 2, which presents the number and percentage of high and low scoring students in each of the eight cells of the attribution cube, indicates that the students differed significantly in their emphasis of the three dimensions; $\chi^{2}(7)=61.65, p<.0001$. For high scoring students, the most frequently chosen cell of the attribution cube suggests that the outcome was low in distinctiveness and consistent with past scores but better than the scores of the other students in the class. For low scoring students, attributions were nearly equally divided between two of the eight attribution cells: high distinctiveness/low consistency/low consensus and high distinctiveness/high consistency/high consensus.

Table 2

Number and Percentage of Students in Each of the Eight Cells of the Attribution Cube

\begin{tabular}{|c|c|c|c|c|c|c|c|c|c|}
\hline \multirow[b]{3}{*}{ Students } & \multicolumn{4}{|c|}{ Low distinctiveness } & \multicolumn{4}{|c|}{ High distinctiveness } & \multirow[b]{3}{*}{ Total } \\
\hline & \multicolumn{2}{|c|}{ Low consistency } & \multicolumn{2}{|c|}{ High consistency } & \multicolumn{2}{|c|}{ Low consistency } & \multicolumn{2}{|c|}{ High consistency } & \\
\hline & $\begin{array}{l}\text { Low } \\
\text { con- } \\
\text { sensus }\end{array}$ & $\begin{array}{l}\text { High } \\
\text { con- } \\
\text { sensus }\end{array}$ & $\begin{array}{l}\text { Low } \\
\text { con- } \\
\text { sensus }\end{array}$ & $\begin{array}{l}\text { High } \\
\text { con- } \\
\text { sensus }\end{array}$ & $\begin{array}{l}\text { Low } \\
\text { con- } \\
\text { sensus }\end{array}$ & $\begin{array}{c}\text { High } \\
\text { con- } \\
\text { sensus }\end{array}$ & $\begin{array}{c}\text { Low } \\
\text { con- } \\
\text { sensus }\end{array}$ & $\begin{array}{c}\text { High } \\
\text { con- } \\
\text { sensus }\end{array}$ & \\
\hline \multicolumn{10}{|l|}{ Low scoring } \\
\hline$n$ & 7 & 4 & 6 & 12 & 25 & 20 & 12 & 26 & 112 \\
\hline$\%$ & 6.2 & 3.6 & 5,4 & 10.7 & 22.3 & 17.9 & 10.7 & 23.2 & 100 \\
\hline \multicolumn{10}{|l|}{ High scoring } \\
\hline$n$ & 13 & 18 & 32 & 28 & 6 & 9 & 5 & 9 & 120 \\
\hline$\%$ & 10.8 & 15.0 & 26.7 & 23.3 & 5.0 & 7.5 & 4.2 & 7.5 & 100 \\
\hline
\end{tabular}


To more clearly establish the relationship between test score and the eight cells of the attribution cube, a generalized least squares procedure was used to produce chi-square estimates for each classification variable and interaction of classification variables in the design (Grizzle \& Williams, 1972; this method is available in SAS79 under the Funcat procedure; Sall, 1979). This analysis revealed that the overall significant relation was produced by two underlying effects: the significant contingency between distinctiveness and test score, $\chi^{2}(1)=47.20, p<$ .0001 , and the significant contingency between consensus, consistency, and test score, $\chi^{2}(1)=3.88, p<.05$. These two effects are discussed below.

Distinctiveness and test score. Looking first at the relationship between distinctiveness and score, students who performed poorly on the test were more likely to claim their outcome was distinctive rather than nondistinctive $(74.1 \%$ vs. $25.9 \%)$. In other words, although they had done poorly on this particular test, they maintained they were doing better in their other subjects. High scorers, in contrast, rated their scores as low rather than high in distinctiveness $(75.8 \%$ vs. $24.2 \%$ ).

Consensus, consistency, and test score. Collapsing across distinctiveness, Table 2 suggests that the majority of the high scoring students claimed their grade was consistent, rather than inconsistent, with past exam grades $(61.7 \%$ vs. $38.8 \%)$. Low scores, however, were split 50-50 across the high consistency/low consistency dimension, but differences became more apparent when consensus was taken into consideration. Of the low scorers who rated their score as consistent, $67.9 \%$ added that the rest of the class was also getting low grades-an attributional pattern that suggests the source of the poor performance lies in external factors such as the quality of the testing procedures or the classroom instruction. On the other hand, the low scorers who rated their score as inconsistent with previous exam performances were nearly equally divided along the high consensus/low consensus dimension (57.1\% vs. $43.9 \%$ ).

Discussion. As theory and past research suggest (e.g., Kelley, 1971), low scorers' de- scriptions of their performance in terms of the three dimensions of Kelley's attributional model (1967) placed them in the external attribution cells of the cube. They either claimed their score was unlike the grades they were earning in their other classes (high distinctiveness), similar to their past grades and other students' grades (high consistency/high consensus), or unlike past grades and lower than other students' scores (low consistency/low consensus). Most of the successful students, in contrast, described their performance as low in distinctiveness, suggesting that they usually perform well in their college classes. These four attributional patterns accounted for $81.9 \%$ of all the students surveyed.

These results lend partial support to $\mathrm{Hy}$ potheses 1 and 2, but they also suggest that distinctiveness may play a larger role in attributional processes following task performance than was formerly supposed. As predicted, high scorers tended to congregate in the low distinctiveness/low consensus/ high consistency cell, but overall they clustered in the low distinctiveness cells more than the high distinctiveness cells. Furthermore, while over $40 \%$ of the low scorers described their grade as high in both distinctiveness and consensus, again the distinctiveness dimension took precedence over the remaining dimensions. In addition, although these findings suggest that students' descriptions of their outcomes differed depending on what grade they received, the source of this attributional "bias" remains unclear. Although several perspectives propose that students differentially perceive the causes of success and failure to protect and maximize their sense of self-worth (Covington \& Berry, 1976) or self-identity (Forsyth, 1980), logical information processing heuristics could account for the differences that were obtained in this investigation (Miller \& Ross, 1975). To more adequately investigate questions related to the logical information processing versus selfesteem debate in attribution research (Weary, 1979), future investigators should obtain baseline information concerning distinctiveness, consistency, and consensus, and then contrast this "objective" data with students' perceptions. Without such unbi- 
ased measurements, questions concerning egocentrism are difficult to resolve.

\section{Attributions and Expectations}

The expectations of high and low scoring students in the eight cells of the attribution cube were examined in a 2 (score) $\times 2$ (distinctiveness) $\times 2$ (consistency) $\times 2$ (consensus) analysis of variance procedure. ${ }^{1}$ Naturally, high scoring students reported more positive expectations than low scoring students; $F(1,214)=13.99, p<.001$. The respective means were 7.5 and 6.6 . However, the four-way interaction of score, distinctiveness, consistency, and consensus also reached significance, $F(1,214)=5.39, p<$ .05 , and is presented in Figures 2 and 3 . As Figure 2 demonstrates, when students believed their score was consistent with past scores, expectations tended to match outcomes. Those who did poorly reported lower expectations than those who did well, irrespective of perceived distinctiveness and consensus; the simple $F(1,214)$ comparing high scoring students' exepctations with low scoring students' expectations was 13.76 , ( $p$ $<.001$ ). Thus, when consistency was high, the effects of consensus and distinctiveness were, in general, overwhelmed. The only exception to this overall effect of consistency occurred among high scoring students; those who believed their score was low in terms of distinctiveness and consensus were more positive in their expectations than the other high scoring students, $F(1,214)=4.01$, $p<.05$.

When students felt their achieved score was inconsistent with previous test scores, the impact of distinctiveness and consensus was more marked. As Figure 3 depicts, even under conditions of low consistency, high scoring students were still quite positive in their expectations unless they also believed their score was highly distinctive and low in terms of consensus, $F(1,214)=3.98, p<.05$. Among the low scoring, low consistency subjects, the more negative expectations were reported by those who felt their low score was similar to grades they had received in other classes (low distinctiveness) and relatively unique in comparison to other students' scores (low consensus). In con- trast, low scoring/low consistency/low distinctiveness/high consensus students expressed more positive expectations; $F(1,214)$ $=4.62, p<.05$.

Discussion. Overall, the prediction that consistently would be more closely linked to expectations than either distinctiveness or consistency was supported. If students felt their grade was consistent with previous scores, they assumed their future outcomes would continue at this level--just as $\mathrm{Hy}$ pothesis 3 predicted. However, when an inconsistent grade was obtained, individuals turned to distinctiveness and consensus information to interpret this anomalous score. Although the relationships between the remaining two dimensions of the cube and expectations were particularly intriguing in the low consistency over time cells, Hypothesis 4 only partly accounted for the observed results. First, although the prediction that high scorers in the low distinctiveness and consistency subjects (Hypothesis 4a) was not supported, the obverse prediction was congruent with the findings; high scoring students who thought their grade was better than grades in their other classes (distinctive) but unlike other students' performances (low consensus) reported less positive expectations than the other high scoring students.

Second, as Hypothesis $4 \mathrm{~b}$ predicted, low scoring students who understood that the outcome was a usual performance and worse than most of the other students' grades (low distinctiveness and consensus) reported the most negative expectations of the subjects who reported low consistency over time. Unexpectedly, however, low scoring subjects who felt their score was nondistinctive but similar to many other students' grades reported highly positive expectations. Speculating, these students may have recognized that they were essentially "average" students, but they could obtain high scores (as they had on the previous tests) in this class if the instructor, recognizing that many

1 This analysis used a least-squares regression procedure that adjusted each effect for effects of equal or lower order so that the results would not be biased by the unequal $n \mathrm{~s}$ of the factorial design. 
students were doing poorly (high consensus), made the tests easier.

\section{Affective Reactions}

The 16 affect items were averaged to yield an overall affect score that was submitted to a $2 \times 2 \times 2 \times 2$ least squares analysis of variance. ${ }^{2}$ As anticipated, a significant main effect of score was obtained, $F(1,215)=$ $154.23, p<.0001$. Consistent with past research (e.g., Forsyth \& McMillan, 1981), students who received high grades on the test reported more positive levels of affect (e.g., more happy, contented, competent, fulfilled, etc.) than low scoring students; the means were 6.9 and 4.1 , respectively. Although a significant distinctiveness main effect indicated that low distinctive outcomes were associated with more positive affect than high distinctive outcomes $(p<$ .05 ), the interaction of distinctiveness and outcome, $F(1,215)=4.46, p<.05$, reached significance, since this effect was much more pronounced when scores on the test were high rather than low. The low versus high distinctiveness means were 4.4 and 4.0 for the low scoring students, but 7.2 and 6.1 for the high scoring students.

The only other effect that reached significance in the analysis of variance was a three-way interaction of the three attribution variables - distinctiveness, consistency, and consensus, $F(1,215)=4.91, p<.05$. As previously noted, when outcome is held constant, high distinctive scores are associated with less positive affect than low distinctive scores (see Table 3). However, the affect level in the high distinctiveness/low

Table 3

Attributions and Affect

\begin{tabular}{|c|c|c|c|c|}
\hline \multirow[b]{2}{*}{$\begin{array}{c}\text { Distinctive- } \\
\text { ness }\end{array}$} & \multicolumn{2}{|c|}{ Low consistency } & \multicolumn{2}{|c|}{ High consistency } \\
\hline & $\begin{array}{l}\text { Low } \\
\text { con- } \\
\text { sensus }\end{array}$ & $\begin{array}{l}\text { High } \\
\text { con- } \\
\text { sensus }\end{array}$ & $\begin{array}{l}\text { Low } \\
\text { con- } \\
\text { sensus }\end{array}$ & $\begin{array}{c}\text { High } \\
\text { con- } \\
\text { sensus }\end{array}$ \\
\hline Low & $6.3_{\mathrm{a}}$ & $6.3_{\mathrm{a}}$ & $6.8_{\mathrm{a}}$ & $6.3_{\mathrm{a}}$ \\
\hline High & $3.9 \mathrm{c}$ & $4.9 \mathrm{~b}$ & $4.8_{\mathrm{b}}$ & $4.6_{\mathrm{b}}$ \\
\hline
\end{tabular}

Note. Higher means indicate more positive affect. Means without a common subscript differ at the .05 level.

\section{HIGH CONSISTENCY OVER TIME}

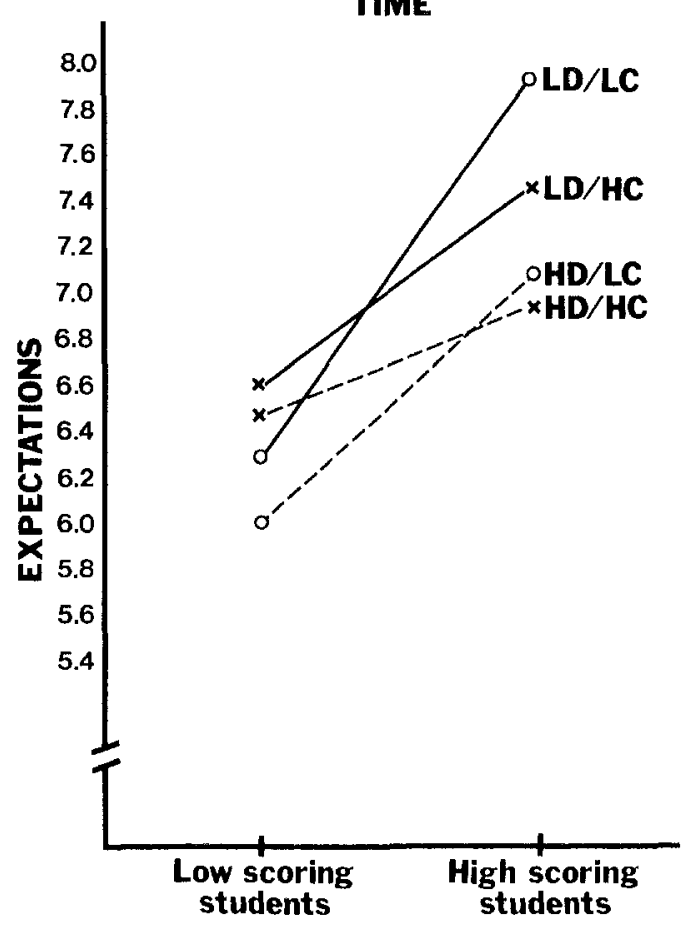

Figure 2. Attributions and expectations for high consistency, $\quad(\mathrm{LD} / \mathrm{LC}=$ low distinctiveness/low consensus; LD $/ \mathrm{HC}=$ low distinctiveness/high consensus; $\mathrm{HD} / \mathrm{LC}=$ high distinctiveness/low consensus; $\mathrm{HD} / \mathrm{HC}$ $=$ high distinctiveness/high consensus.)

consistency/low consensus condition was significantly lower than all the other conditions $(p<.05)$. Although, of course, the successful students in this cell of the attribution cube felt better than most of the low scoring students, their affect mean was lower than that of the high scoring students in the other cells of the cube. Similarly, the failure students in this cell were less positive than the other failure students.

Discussion. Although both of the obtained interactions emphasize the impact of distinctiveness on affective reactions to ex-

\footnotetext{
${ }^{2}$ When these 16 items were submitted to principal components factor analysis, only one major factor was obtained. Its eigenvalue was 12.02 and it accounted for $75.2 \%$ of the common variance. The second factor had an eigenvalue of only 74 and accounted for less than $5 \%$ of the common variance. Hence it was assumed that the items all measured a single affect dimension; the alpha coefficient of the affect "scale" was .952.
} 
amination feedback, these findings are only partly consistent with Hypotheses 5 and 6 . As was the case with student distribution patterns in the eight cells of the cube, the distinctiveness dimension tended to overwhelm the other two dimensions. In simple terms, students generally responded negatively to unexpected, surprising grades.

The three-way interaction of distinctiveness, consensus, and consistency is especially intriguing because it was not qualified by test score. Although a variety of factors may account for the pattern of means that was obtained, one plausible explanation suggests that two very different processes were involved. Focusing first on the high scorers, these students may have felt that although they managed to get a good grade on this test, their future performance would not be as positive. On past tests they had performed poorly (low consistency), they were

\section{LOW CONSISTENCY OVER TIME}

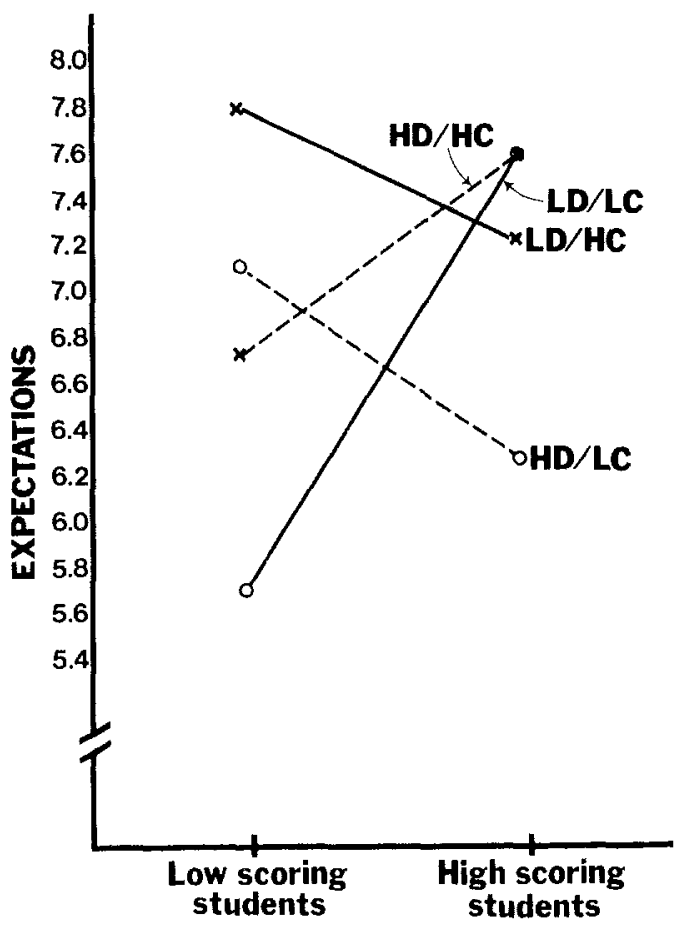

Figure 3. Attributions and expectations for low consistency. $\quad(\mathrm{HD} / \mathrm{HC}=$ high distinctiveness $/$ high consensus; LD/LC = low distinctiveness/low consensus; $\mathrm{LD} / \mathrm{HC}=$ low distinctiveness/high consensus; $\mathrm{HD} / \mathrm{LC}$ $=$ high distinctiveness/low consensus.) not doing well in other classes (high distinctiveness), yet they had managed to perform better than many other people in their class (low consensus). Apparently these students believed their next performance would be less successful, and therefore experienced more negative affect than the other high scoring students. Figure 3 supports this interpretation because it indicates that the high scoring students in this cell of the cube (low consistency/high distinctiveness/low consensus) reported more negative expectations than the other successful students, $F(1,214)=3.98, p<.03$.

The low scoring students in the same cell of the cube, on the other hand, felt they were doing well in other classes, were doing well in this particular class, and yet had done poorly on the test that many other students had successfully completed. Their affective responses, then, were not produced by their negative expectations concerning future performance but by the discrepancy between their past performance and their current performance.

\section{Conclusions}

The predictive utility of the attribution cube, both in describing attributional patterns and predicting associated expectations and affects, was generally confirmed in this investigation. 'To a large extent, students' distribution patterns in the eight cells of the cube and their affective reactions were closely linked to the distinctiveness dimension. Although effects of two other components of the cube model-consensus and consistency - were in evidence, the clear-cut distinctiveness effects suggested that (a) high scoring students prefer to believe their grade is a nondistinctive (typical) academic achievement, (b) low scoring students prefer to believe their grade is a distinctive (atypical) outcome, and (c) students react more negatively, at an affective level, to outcomes that are high rather than low in distinctiveness. The general power of distinctiveness did not hold, however, for expectations of future performance in the classroom. In this case, the consistency over time dimension tended to dominate the other two axes of the cube, as other researchers have reported (McArthur, 1972). To elaborate on a pos- 
sible model of the formation of expectations in educational settings, the current findings suggest that students first assess the consistency of their performance in a class. If several tests have been taken and scores have been comparable, then the students assume that their future grades will mirror their past grades; failing students expect to fail some more, and successful students expect to continue succeeding. If, however, students have obtained a mixture of good and bad grades, then they will turn to other sources of causal information, most notably distinctiveness and consensus, to establish reasonable expectations. For students who have just received negative exam feedback, low distinctiveness and high consensus combine to yield fairly positive expectations, whereas low distinctiveness and low consensus combine to produce negative expectations. In contrast, high scoring students expect to continue to do well on later tests, unless they believe their recent performance was highly distinctive and unlike the performances of most of the other students in the class.

These findings have both basic and applied implications. First, the results support the predictive validity of Kelley's theoretical model of attributions. The distribution of respondents in the cube's three axes was, for the most part, consistent with the model's predictions. Second, although previous research has examined the attributional impact of the three axes in laboratory settings or in responses to paper-and-pencil vignettes (e.g., Stevens \& Jones, 1976; McArthur, 1972), the success of the model in this study provides evidence of external validity. Third, while several studies have raised doubts about the attributional importance of consensus information (McArthur, 1972; Nisbett \& Borgida, 1975), consistent relationships between consensus, affect, and expectations were detected in this investigation.

In addition to these theoretical implications, the findings also yield suggestions concerning attributions, affect, and classroom motivation. For example, the cube very clearly specifies when failure will be most devastating for students, and when students will not be encouraged by their successes. Furthermore, this research suggests that teachers should be sensitive to students' attributional processes and provide them with situational information that fosters positive, achievement facilitating causal inferences. To generalize beyond the current study, students may be more receptive to attributional information when their performances are of uneven quality, and in these instances the teacher may heighten motivation by emphasizing the importance of sustained effort and ability. When students' outcomes are more consistently good or bad, then attributional information (including consensus and distinctiveness data) may be relatively less influential. Although these possibilities are intriguing, a complete description of the implications of attributional processes in the educational setting must be postponed until the many remaining empirical questions have been more fully answered.

\section{References}

Covington, M. V., \& Berry, R. G. Self-worth and school learning. New York: Holt, Rinehart \& Winston, 1976.

Covington, M. V., \& Omelich, C. I. Are causal attributions causal? A path analysis of the cognitive model of achievement motivation. Journal of Personalily and Social Psychology, 1979, 37, 1487-1504.

Forsyth, D. R. The functions of attribution. Social Psychology Quarterly, 1980, 43, 184-189.

Forsyth, D. R, \& McMillan, J. H. Attributions, affect, and expectations: A test of Weiner's three-dimensional model. Journal of Educational Psychology, $1981,73,393-403$.

Forsyth, D. R., \& Schlenker, B. R. Attributing the causes of group performance: Effects of performance quality, task importance, and future testing. Journal of Personality, 1977, 45, 220-236.

Grizzle, J. E., \& Williams, O. D. Log linear models and tests of independence for contingency tables. Biometrics, 1972, 28, 137-156.

Heider, F. The psychology of interpersonal relations. New York: Wiley, 1958.

Jones, E. E. Update of "From acts to dispositions: The attribution process in person perception." In L. Berkowitz (Ed.), Cognitive theories in social psychology. New York: Academic P'ress, 1978.

Jones, E. E., \& Davis, K. E. From acts to dispositions: The attribution process in person perception. In L. Berkowitz (Ed.), Advances in experimental social psychology (Vol. 2). New York: Academic Press, 1965.

Kelley, H. H. Attribution theory in social psychology. In D. Levine (Ed.), Nebraska symposium on motivation. Lincoln: University of Nebraska Press, 1967. 
Kelley, H. H. Attribution in social interaction. Morristown, N.J.: General Learning Press, 1971.

McArthur, L. A. The how and what of why: Some determinants and consequences of causal attribution. Journal of Personality and Social Psychology, 1972, 22, 17-193.

Miller, D. T., \& Ross, M. Self-serving biases in the attribution of causality: Fact or fiction? Psychological Bulletin, 1975, 82, 213-225.

Nisbett, R. E, \& Borgida, E. Attribution and the psychology of prediction. Journal of Personality and Social Psychology, 1975, 32, 932-943.

- Orvis, B. R., Cunningham, J. D., \& Kelley, H. H. A closer examination of causal inference: The roles of consensus, distinctiveness, and consistency information. Journal of Personality and Social Psychology, 1975, 32, 605-616.

Ostrove, N. Expectations for success on effort-determined tasks as a function of incentive and performance feedback. Journal of Personality and Social Psychology, 1978, 36, 909-916.

Sall, J, P. Funcat procedure. In J. T. Helwig \& K. A.
Council (Eds.), SAS user's guide. Raleigh, N.C.: SAS Institute, 1979.

Stevens, L., \& Jones, E. E. Defensive attribution and the Kelley cube. Journal of Personality and Social Psychology, 1976, 34, 809-820.

Weary, G. Self-serving attributional biases: Perceptual or response distortions? Journal of Personality and Social Psychology, 1979, 37, 1418-1420.

Weiner, B. A theory of motivation for some classroom experiences. Journal of Educational Psychology, $1979,71,3-25$.

Weiner, B., Russel, D., \& Lerman, D. Affective consequences of causal ascriptions. In J. H. Harvey, W. J. Ickes, \& R. F. Kidd (Eds.), New directions in attribution rersearch (Vol. 2). Hillsdale, N.J.: Erlbaum, 1978.

Weiner, B., Russel, D., \& Lerman D. The cognitionemotion process in achievement-related contexts. Journal of Personality and Social Psychology, 1979, 37, 1211-1220.

Received September 11, 1980 